\title{
Discrepancy between actual and estimated speeds of drivers in the presence of child pedestrians
}

\section{N Harré}

Objectives: First, to measure the speeds of vehicles with and without children on the footpath, and second to compare these with drivers' estimates of how fast they would go in these conditions.

Design: The speeds of vehicles in three conditions: control (no children present), children playing with a ball on the footpath, and children waiting to cross the road, were measured using speed tubes during two 55 minute sessions. Drivers' estimates of their speeds were measured with a questionnaire. Setting: Speeds were measured on a main road in Auckland, New Zealand. The questionnaire was conducted at another time with drivers stopping for petrol approximately 500 metres from the measurement site.

Subjects: A total of 1446 speed measurements were taken and 93 drivers' questionnaire responses were analysed.

Results: The mean free speed of vehicles in the control condition was $55.60 \mathrm{kph}$, with drivers' estimates being $56.37 \mathrm{kph}$. When children were playing with a ball the measured speed was 54.29 $\mathrm{kph}$ and the estimated speed $39.27 \mathrm{kph}$. When children were waiting to cross the measured speed

Correspondence to: Dr Niki Harré, Department of Psychology, University of Auckland, Private Bag 92019, Auckland, New Zealand;

n.harre@auckland.ac.nz was $52.78 \mathrm{kph}$, estimated speed $34.02 \mathrm{kph}$. Analyses indicated that there were significant differences between measured and estimated speeds.

Conclusions: New Zealand drivers make inadequate speed adjustments in the presence of children, despite probably believing they do so. Establishing specific rules about appropriate speeds around children and highlighting to drivers the discrepancy between their attitudes and behaviour are two intervention strategies suggested.

$\mathrm{P}$ edestrian crashes are a major cause of child mortality and morbidity in New Zealand ${ }^{1}$ and elsewhere..$^{2-4}$ One significant contributor to these crashes is vehicle speed. Studies comparing child injury sites with non-injury sites in Australia $^{5}$ and New Zealand ${ }^{6}$ have found a strong association between vehicle speed and injury risk. An analysis of the impact of vehicle speed on injury found that at $40 \mathrm{kph} 25 \%$ of crashes are likely to be fatal, while at $50 \mathrm{kph}$ this rises to $85 \%$.

Unfortunately there is little evidence that drivers understand the dangers of speed around child pedestrians and slow down in their presence. In a US study of pedestrian injuries it was found that even on local streets and in residential zones, nearly $20 \%$ of children were struck by vehicles exceeding 30 mph ( 50 kph). ${ }^{8}$ A Swedish study of driver speed and yielding to pedestrians at marked crossings found the age of the pedestrian made no difference to driver behaviour. ${ }^{9}$ Observations of pedestrian and driver behaviour in Nottingham, England found that pedestrians appeared to take the most effective avoidance action in potential collisions, and the age of the pedestrian had little impact on driver behaviour. ${ }^{10}$ Another study conducted in the same city at five junior schools (age range 3-11 years), found speeds were significantly higher in the presence of an adult pedestrian than when no pedestrian was present, with the presence of a child producing no significant change in speed.

One question that has not been empirically explored is whether or not drivers actually realize how seldom they reduce speed in the presence of child pedestrians. There is evidence that drivers overestimate the speeds of others, ${ }^{12}$ and one study of New Zealand drivers found $85 \%-90 \%$ claimed to drive below the average speed. ${ }^{13}$ In a Swedish study, 5\% of drivers were observed giving way to pedestrians at marked crossings, which is in stark contrast to a report cited by the author in which $67 \%$ of the 1266 Swedish drivers surveyed claimed to give way to pedestrians at crossings "very often" or "always".

The study described in this paper had two primary aims. First, to measure the speed of New Zealand drivers with and without children on the footpath, and second to compare the measured speeds with drivers' estimates of how fast they would go in the presence of child pedestrians. The prevention implications of discrepancies between actual and estimated speeds will be addressed in the discussion.

\section{METHODS}

Study 1: Measured speed of vehicles in the presence of child pedestrians

The study took place on a moderately busy road in Auckland City, New Zealand. Approximately 700-750 vehicles traveled in the direction of interest during each 55 minute period in which speeds were measured. The total road width was approximately 14.5 metres, including a 2.1 metre flush lane, a 3.2 metre bus lane on the opposite side of the road, and a single lane in each direction. The footpath next to where the measurements were taken was 3 metres wide. The legal speed limit was $50 \mathrm{kph}$, which is standard for urban roads in New Zealand. The site was chosen for the following reasons:

- A steady flow of traffic meant a large number of measurements could be obtained in a relatively short time. This was considered essential with children involved.

- Oncoming vehicles had an unimpeded view of the footpath at all times, due to the site being 100 metres after a corner, the presence of no parking lines, and the absence of any other obstructions.

- The site was not a natural crossing point for pedestrians. This was considered important to minimize the possibility of other pedestrians influencing driver speeds. 


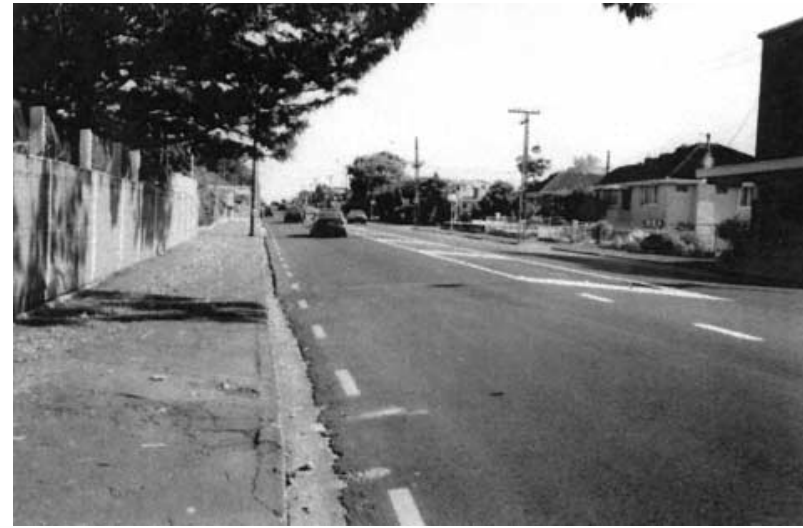

Figure 1 Control conditions.

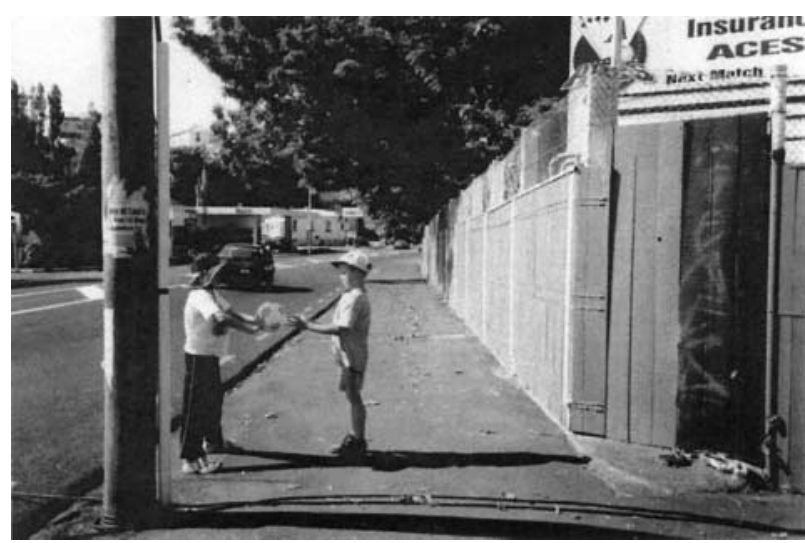

Figure 2 Children playing with a ball.

- The presence of a large fence allowed the equipment and people to be hidden from view.

Vehicle speeds were measured using speed tubes that were linked to a lap top computer hidden behind the fence. The computer showed the time and speed of the vehicles as they went over the tubes. It also measured the gap (in seconds) between vehicles. Measurements took place on two Thursday afternoons from 3.35-4.30 pm. This time was chosen to ensure reasonable traffic flow but to avoid after school pedestrians, and the commuter rush hour. There were three conditions:

1. Control: no children present (see fig 1).

2. Children playing with a ball on the footpath (see fig 2).

3. Children waiting to cross (see fig 3).

The children were a (smaller than average) 10 year old girl and a 7 year old boy. When the children were present, vehicles approaching the tubes would have been able to see them immediately on turning the corner. They stood within 1 metre of the tubes at all times, so the measured speed of the vehicles corresponded exactly to the speed with which they past the children. On each day the conditions were run in five minute slots in the following order: 1, 2, 1, 3, 1, 2, 3, 1, 2, 1, 3. During the control condition, the children rested behind the fence, out of view of the oncoming vehicles. The weather was sunny both days.

The flow of vehicles was steady, with a total of 1446 vehicle speeds recorded. Sometimes vehicles traveled in a "platoon", however, there were no incidences in which there was sufficient traffic build up for vehicles to slow to a crawl or come to a stop. There were occasional pedestrians on the footpath. They were adults or teenagers who did not show any signs of erratic behaviour and no pedestrians attempted to cross the road during the study.

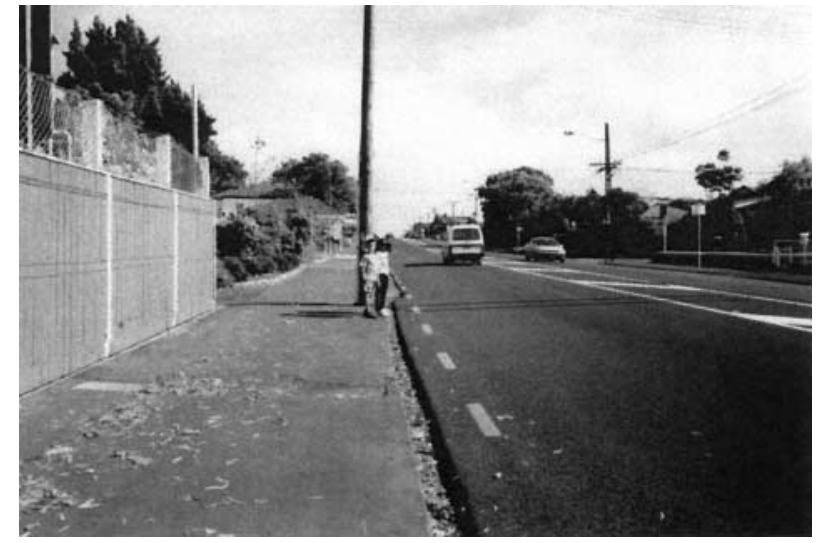

Figure 3 Children waiting to cross.

\section{Study 2: Drivers' perceptions of the speeds they travel} past children

In order to test if drivers' reports of the speed they would travel with children present were in line with the actual speeds recorded, a questionnaire was delivered to 100 drivers stopping at a petrol station, approximately 500 metres from the site of the speed measurement study. The questionnaire had the following instructions: "When you are driving on a main road in Auckland (for example, New North Rd, Sandringham Rd) what speed do you go?" (note: Sandringham Rd was the site of the speed measurement study).

This was followed by a set of conditions under which they were asked to estimate their usual speed:

1. In normal traffic conditions during the day or weekend. 2. When there are children playing with a ball on the footpath. 3. When there are children waiting to cross the road.

4. When there is an elderly pedestrian in the middle of the road.

5. When there is heavy traffic and a lot of cars pulling in and out.

Questions 4 and 5 were asked to obscure the main purpose of the questionnaire and to allow an examination of any question order effects. In one version the questions were asked in the order listed above. In a second version, the questions were asked in the following order: 1, 4, 5, 2, 3. The questionnaire also asked for participants' gender and age group.

The final sample was made up of 67 male and 26 female participants, with 28 participants aged 16-25 years, 47 aged 26-45, and 18 aged 46 years and over. The seven participants who answered "to conditions" or "slow" for any of questions $1-4$ were eliminated.

\section{RESULTS}

Study 1: Measured speed of vehicles in the presence of child pedestrians

In order to restrict the analysis to vehicles that were traveling at freely chosen speeds, all vehicles less than or equal to 2.5 seconds behind the vehicle in front were eliminated. The mean, 50th and 85th percentile speeds can be seen on table 1 . An analysis of variance was carried out to test if there was any statistically significant difference between conditions. A difference was found $\mathrm{F}(2,764)=10.89, \mathrm{p}<0.001$. Post-hoc Tukey HSD tests indicated that the control condition was significantly different from children waiting to cross (95\% confidence interval for the mean difference, 1.39 to 4.24 ), but that it was not different from children playing with a ball, and the two conditions with children were not significantly different from each other. 
Table 1 Comparison between measured speeds and estimated speeds with and without children on the footpath (speed limit $50 \mathrm{kph}$ )

\begin{tabular}{|c|c|c|c|c|}
\hline & \multirow[b]{2}{*}{ No } & \multirow[b]{2}{*}{ Mean (SD) } & \multicolumn{2}{|c|}{ Percentiles } \\
\hline & & & 50 th & 85 th \\
\hline \multicolumn{5}{|l|}{ No children present } \\
\hline Measured speed & 345 & $55.60(7.47)$ & 55.50 & 62.33 \\
\hline Estimated speed & 93 & $56.37(6.17)$ & 55.00 & 60.00 \\
\hline \multicolumn{5}{|c|}{ Children playing with ball } \\
\hline Measured speed & 209 & $54.29(6.15)$ & 54.90 & 59.45 \\
\hline Estimated speed & 93 & $39.27(12.52)$ & 40.00 & 50.00 \\
\hline \multicolumn{5}{|c|}{ Children waiting to cross } \\
\hline Measured speed & 213 & $52.78(6.83)$ & 53.40 & 59.16 \\
\hline Estimated speed & 93 & $34.02(17.43)$ & 40.00 & 50.00 \\
\hline
\end{tabular}

The percentage of vehicles traveling at high speeds was also examined. In the control condition, $24 \%$ went faster than 60 $\mathrm{kph}, 54 \%$ faster than $55 \mathrm{kph}$, and $81 \%$ faster than $50 \mathrm{kph}$. When the children were waiting to cross and playing with a ball $11 \%$ and $14 \%$ respectively went faster than $60 \mathrm{kph}, 41 \%$ and $48 \%$ respectively went faster than $55 \mathrm{kph}$, and $75 \%$ and $79 \%$ respectively went faster than $50 \mathrm{kph}$. This suggests that the children's presence may have had a greater impact on those traveling $10 \mathrm{kph}$ or more over the limit, than those still speeding, but traveling within $10 \mathrm{kph}$ of the limit.

\section{Study 2: Drivers' perceptions of the speeds they travel} past children

The results of the questionnaire participants' estimates can be seen on table 1, along with the measured free speeds of drivers in the earlier study.

A multivariate analysis was conducted to see if there was any difference between versions of the questionnaire, men and women and the age groups on each of the three items of interest. This indicated that only questionnaire version was significant $F(3,79)=3.22, p<0.05$. Univariate analyses suggested that the difference in version was with regard to the item about children playing with a ball $F(1,81)=4.21$, $\mathrm{p}<0.05$. Those participants who were given the child items first gave a mean speed of $42.76 \mathrm{kph}$ for children playing with a ball with those participants who were given the child items second giving a mean speed of $35.38 \mathrm{kph}$ for this item.

Table 1 shows that the participants in the questionnaire were probably reasonably accurate in estimating their usual speed on a main road in Auckland. However, there were clear discrepancies between their estimates of the speed with which they would travel past children and the measured speeds. Analysis of variance indicated that there was indeed no difference between estimated and actual speeds in the control condition, but there were differences between these in the children playing with a ball $\mathrm{F}(1,300)=195.34, \mathrm{p}<0.001$ and waiting to cross $\mathrm{F}(1,304)=183.12, \mathrm{p}<0.001$ conditions.

\section{DISCUSSION}

In keeping with previous studies, ${ }^{911}$ minimal reductions in speed were found in the presence of child pedestrians. While there was a smaller percentage of drivers traveling faster than $60 \mathrm{kph}$ when children were present than when they were not, and drivers did travel an average of $2.82 \mathrm{kph}$ slower when children were trying to cross the road than when there were no children present, their mean speed in this condition was still $52.78 \mathrm{kph}$, at which a likely $85 \%$ of collisions would be fatal. ${ }^{7}$ Drivers did not travel significantly more slowly on average when children were playing with a ball on the footpath than with no children present.

There was also evidence that drivers may believe they have a different response to the presence of children than is actually the case. The median speed they estimated traveling past children was 13.4-14.9 $\mathrm{kph}$ slower than the measured median speeds. There are a number of possible reasons for this discrepancy. First, drivers may simply not be aware of their driving habits. When asked directly they believe they treat children as worthy of a response, but in actuality they are so used to children behaving responsibly in traffic that they barely even notice them in a complex road environment. It is notable that although children generally do behave responsibly in traffic and may be good at compensating for their limitations at judging the speed and distance of approaching vehicles ${ }^{14}{ }^{15}$ by making cautions decisions, ${ }^{15}$ they are potentially impulsive and may be more readily distracted from adequate monitoring of the traffic environment than adults. $^{14-16}$ In studies that have analyzed official child pedestrian injury records, the major cause of these crashes is usually described as "mid-block dart outs". ${ }^{13} 17$ 18 Such "dart outs" are probably extremely unusual, so drivers have effectively learned, or rather over-learned, that children can be relied upon to keep out of their path.

Second, the participants may have been responding to the questions in a socially desirable manner. They know they should slow down for children, although they may also know they rarely do this. Third, the questionnaire respondents may have constructed a different mental image of the scenarios being referred to than was actually the case. It is possible they imagined younger or more children. The latter is particularly significant as previous studies have shown a large number of pedestrians do tend to slow drivers down. ${ }^{911} 19$

This study suggests that drivers have an understanding that children should be responded to but they do not share a set of rules about what is appropriate. Apart from the discrepancy between measured and estimated speeds, there were other indications from the questionnaire data for the absence of shared rules. One of these was the question order effect. Drivers who were asked about their speed when children were playing with a ball after they had been asked about the elderly pedestrian and heavy traffic, gave estimates $7.38 \mathrm{kph}$ lower on average than those who received the child items first. There was also a great deal of variance in participants' responses to the items concerning speed around children, shown by standard deviations that were at least twice that found when actual speeds in the presence of children were measured or when participants were asked about their speed in normal conditions. Further research in this area could examine more closely what lies behind this apparent confusion on the part of drivers, including their beliefs about children's capabilities in traffic and about their legal responsibilities to take due care.

\section{IMPLICATIONS FOR PREVENTION}

The absence of shared rules about behaviour around children suggests a potential focus for prevention efforts. Fuller 
suggested that in order to combat the "learned riskiness" that comes from drivers gaining rewards for ignoring potential risks (such as child pedestrians), safer behaviours should be specified and rule following encouraged and rewarded. ${ }^{20}$ It may also be effective to punish rule breaking (most obviously through enforcement). In the case of drivers' responses to child pedestrians this could include publicity that suggests an appropriate speed around children (of say $40 \mathrm{kph}$, the medium estimated speed given by drivers in this study) or a suggestion to lower speed by $5-10 \mathrm{kph}$ in the presence of children. Even issuing fines when drivers exceed the current speed limit of 50 $\mathrm{kph}$ in the presence of children, rather than allowing a leeway of $10 \mathrm{kph}$ over the limit as is usual practice in New Zealand, would help, given that more than $75 \%$ of the drivers in the current study were exceeding the speed limit when they traveled past the children.

The social psychological theory of cognitive dissonance suggests that people are uncomfortable when they become conscious of a discrepancy between their attitudes and behaviours and they will try to reconcile the two. ${ }^{21}$ Informing drivers through advertising campaigns and in learner driver and defensive driver training programmes that they do not respond to children in the way they might imagine could help induce cognitive dissonance and provide an opportunity for behaviour change. At the very least suggesting to drivers that they may not be as safe as they report could encourage them to believe that pedestrian safety messages actually apply to them, rather than to "other drivers".

Children's behavioural errors in traffic are probably most often the result of impulsiveness and distraction, ${ }^{14-16}$ the very behaviours that arise suddenly and cannot be adequately responded to by fast moving vehicles. While environmental modifications, such as traffic calming, are clearly important, ${ }^{22}$ there are many situations in which such modifications are impractical. This study suggests that drivers probably believe it is desirable to reduce their speed around children. Issuing specific guidelines about appropriate speeds, drawing drivers' attention to the discrepancy between their beliefs and behaviours through existing training programmes and advertising campaigns, and enforcing the actual speed limit in the presence of child pedestrians are potentially promising strategies.

\section{ACKNOWLEDGEMENTS}

This research was funded by the Land Transport Safety Authority of New Zealand and Auckland City. The input of Theo Brandt, Raewyn Fairley, and other members of the Auckland City Pedestrian Safety Campaign working group is gratefully acknowledged. Rita Harré and Max Thomas are thanked for their role on the footpath.

\section{REFERENCES}

1 Kypri K, Chalmers DJ, Langley JD, et al. Child injury mortality in New Zealand 1986-95. J Paediatr Child Health 2000;36:431-9.

\section{Key points}

- Drivers made few speed adjustments in the presence of children, with the majority continuing to travel in excess of the $50 \mathrm{kph}$ speed limit.

- The median estimates drivers gave of the speed they would go when children were on the footpath were 13.4-14.9 km lower than the median measured speeds.

- Issuing specific guidelines about appropriate speeds, drawing drivers' attention to the discrepancy between their beliefs and behaviours and enforcing the actual speed limit in the presence of child pedestrians are potentially promising strategies.

2 Durkin MS, Laraque D, Lubman I, et al. Epidemiology and prevention of traffic injuries to urban children and adolescents. Pediatrics 1999:103:e74.

3 Lightstone AS, Dhillon PK, Peek-Asa C, et al. A geographical analysis of motor vehicle collisions with child pedestrians in Long Beach, California: comparing intersection and midblock incident locations. Inj California: comparing int

4 Stevenson $M$, Iredell $H$, Howat $P$, et al. Measuring community/ environmental interventions: the Child Pedestrian Injury Prevention Project. Inj Prev 1999;5:26-30.

5 Stevenson MR, Jamrozik KJ, Spittle J. A case-control study of traffic risk factors and child pedestrian injury. Int J Epidemiol 1995;24:957-64.

6 Roberts IR, Marshall R, Lee-Joe T. The urban traffic environment and the risk of child pedestrian injury: a case-crossover approach. Epidemiology 1995;6:169-71.

7 Anderson RWG, McLean AJ, Farmer MB, et al. Vehicle travel speeds and the incidence of fatal pedestrian crashes. Accid Anal Prev and the incidence

8 Pitt R, Guyer B, Hsieh C, et al. The severity of pedestrian injuries in children: an analysis of the pedestrian injury causation study. Accid Anal Prev 1990;22:549-59.

9 Várhelyi A. Drivers' speed behaviour at a zebra crossing: a case study. Accid Anal Prev 1998;30:731-43.

10 Howarth $\mathrm{Cl}$, Lightburn A. How drivers respond to pedestrians and vice-versa. In: Oborne DJ, Levis JA, eds. Human factors in transport research. Vol 2: user factors. London: Academic Press, 1980: 363-70.

11 Thomson SJ, Fraser EJ, Howarth Cl. Driver behaviour in the presence of child and adult pedestrians. Ergonomics 1985;28:1469-74.

12 Walton D, McKeown PC. Drivers' biased perceptions of speed and safety campaign messages. Accid Anal Prev 2001;33:629-40.

13 Walton D, Bathurst J. An exploration of the perceptions of the average driver's speed compared with perceived driver safety and driving skill. Accid Anal Prev 1998;30:82 1-30.

14 Connelly ML, Conaglen HM, Parsonson BS, et al. Child pedestrians' Connelly ML, Conaglen HM, Parsonson BS, et al. Child pedes

15 Demetre JD, Lee DN, Pitcairn TK, et al. Errors in young children's decisions about traffic gaps: experiments with roadside simulations. $\mathrm{Br} J$ Psychol 1992;83: 89-202

16 Malek MB, Guyer B, Lescohier I. The epidemiology and prevention of child pedestrian injury. Accid Anal Prev 1990;22:301-13.

17 Kraus JF, Gerken Hooten D, Brown KA, et al. Child pedestrian and bicyclist injuries: results of community surveillance and a case-control study. Inj Prev 1996:2:212-18.

18 Rivara FP. Child pedestrian injuries in the United States. Am J Dis Child 8 Rivara FP. Child

19 Katz A, Zaidel D, Elgrishi A. An experimental study of driver and pedestrian interaction during the crossing conflict. Hum Factors 1975;17:514-27.

20 Fuller R. Learned riskiness. Irish Journal of Psychology 1992;13:250-7.

21 Festinger L. A theory of cognitive dissonance. Stanford, CA: Standford University Press, 1957

22 Roberts I, Ashton T, Dunn R, et al. Preventing child pedestrian injury: pedestrian education or traffic calming? Aust J Public Health 1994:18:209-12. 